\title{
A ECOLOGIA NO PRATO: UMA ANÁLISE ETNOGRÁFICA SOBRE OS CONCEITOS DE ECOGASTRONOMIA E PRAZER
}

\author{
Kamila Guimarães Schneider ${ }^{1}$
}

\begin{abstract}
RESUMO: O tema que estrutura este trabalho é a ecogastronomia. Mais especificamente pretendo discutir o seu conceito e a sua aplicabilidade através das diretrizes e das visões trazidas pelo movimento denominado Slow Food. Para tal é necessário em um primeiro momento trazer uma contextualização sobre o Slow Food. Em seguida discutir como um movimento internacional, que propõem uma alimentação local, se articula com as esferas nacionais e regionais. Desta forma, ver os pontos convergentes e divergentes deste conceito no âmbito brasileiro e regionalizado. Para, enfim, analisarmos como se estabelece as práticas e hábitos cotidianos da produção e do consumo alimentar ecológico dos participantes e consequentemente como teorizam e o que compreendem sobre ecologia e sua ligação com a alimentação.
\end{abstract}

Palavra-Chave: Ecogastronomia, Glocal, Slow Food.

\section{ECOLOGY IN THE DISH: AN ETHNOGRAPHIC ANALYSIS ON THE CONCEPTS OF ECOGASTRONOMY AND PLEASURE}

\begin{abstract}
The structuring theme this work is the eco-gastronomy. More specifically I do intend to discuss its concept and its applicability through the guidelines and visions brought about by the movement called Slow Food. This requires at first bring a contextualization of Slow Food. Then discuss how an international movement, proposing a local feeding, is linked to the national and regional levels. Thus, to see the similarities and the differences of this concept in the Brazilian and regionalized context. To conclude we analyze how to establish the quotidian practices and habits of production and ecological food consumption of participants and consequently to theorize and comprising about ecology and its link with food.
\end{abstract}

Keyword: eco-gastronomy, Glocal, Slow Food.

\section{INTRODUÇÃO}

Durante dezoito meses tive uma imersão dentro do movimento Slow Food. Este trabalho de campo fez com que a gastronomia fosse resignificada através de um novo olhar que ultrapassa as barreiras de uma visão do consumo imediato dos alimentos e da gastronomia

\footnotetext{
1 Bacharel e Licenciatura em Ciências sociais pela Universidade Estadual do Oeste do Paraná, mestra em Antropologia Social pela universidade Federal de Santa Catarina e Especialista em Vigilância em Saúde, pelo programa de Residência Integrada em Saúde da escola de Saúde Pública do estado do Rio Grande do Sul. Contato: kamilaschneider@uol.com.br
} 
apenas voltada para o fim da cadeia produtiva, em que o se alimentar alienadamente era o fim. Busquei, desta forma, entender a alimentação e a própria antropologia pautando-me no sentir em suas mais diferenciadas esferas, não apenas no olhar, mas no degustar, no tatear, no cheirar (Le Breton, 2016). Assim aprendi, vivenciei e, claro, apreciei o que seria a ecogastronomia.

Este tema, a ecogastronomia, acabou presente, direta ou indiretamente, em todos os momentos que realizei o trabalho, tornando necessária uma maior explanação sobre ela. Em cada saída, viagem, reunião, palestra e refeição no campo se discutiam temas vinculados a meio ambiente, território, produção alimentar, desperdício alimentar, relação homem animal, entre outras coisas que se interligam realizando um paralelo entre natureza, cultura e sociedade. Estes conceitos e temas são elementos levantados para embasar e significar a ecogastronomia. Assim pretendo neste trabalho trazer o discurso dos participantes e seus entendimentos sobre a gastronomia ligados a ecologia. Em que essa ecologia vai além do biologismo, somando-se a este a relação do ser humano enquanto ser coletivo e individual.

Contudo não adianta falarmos de ecogastronomia se não trazer de quem e de que espaço estou falando. As vozes que eu trago aqui são dos participantes do Slow Food e, assim, se faz necessário uma contextualização deste grupo e do movimento em si. Contudo por ser um grupo internacional busco partir da minha viagem, para realizar o meu trabalho de campo, através dos ensinamentos e conversas com os participantes que atuam na cidade de Florianópolis, Santa Catarina, Brasil. Pude assim analisar elementos particulares do movimento através de conversas, vivencias e ações realizadas pelo grupo neste local e sua rede de relações com os demais grupos do movimento, tanto no Brasil como no mundo. Para, por fim, trazer a relação que se estabelece entre ecologia e gastronomia como elemento fundamental para o movimento Slow Food.

Devo resaltar que realizei meu trabalho juntamente com o grupo local da cidade de Florianópolis, mas não apenas me restringi a este território e a esses sujeitos. Andei por vários lugares fora da ilha e conheci muitos participantes que não eram da cidade e vinham dar palestras, conhecer e trabalhar com os "manezinhos da ilha", inclusive fora do Brasil. Por isso pude observar vários olhares sobre o meio ambiente, alimentação e socialização entre as

\footnotetext{
2 Termo utilizado para denominar os sujeitos nascidos e criados na Ilha de Florianópolis. Esta denominação tem origem na descendência açoriana que está atrelada a maioria destes sujeitos. E os nascidos na ilha açoriana também carregam a nomenclatura de Marézinhos da Ilha. Mas que a priori era utilizada como denominação pejorativa e com o advento da ilha como rota turística acabou se perdendo o contexto pejorativo e sendo autodenominação, gerando assim uma nova forma identitária. (RIAL, 1988).
} 
pessoas e seus meios. Pois em cada local que fui, inclusive mesmo dentro da cidade, percebese que as pessoas interagem com o meio conforme seus habitus e costumes (Bourdieu, 2006).

\section{SOBRE O MOVIMENTO SLOW FOOD}

O movimento Slow Food nasceu no ano de 1986 quando, em frente à Praça Espanha na capital italiana, é inaugurada uma loja de uma grande empresa de alimentos de Fast Food, gerando forte mobilização entre profissionais ligados a universidades da região. Entre eles estava Carlo Petrini um dos maiores expoentes responsável pela movimentação e a criação do movimento. Apesar do estopim ter ocorrido em Roma, à organização do movimento se deu na região piemontesa da Itália, abrangendo três cidades Bra, Alba e Barolo. Esta localização é estratégica e vem através de uma militância antiga de Petrini e sua relação com os produtores da região. Petrini era filiado do Partido Comunista Italiano (CCI) e foi vereador pelo mesmo partido. Foi neste período que começou a realizar laços mais estreitos com camponeses tradicionalistas e com a enogastronomia ${ }^{3}$ local, como nos demostra Andrews (2010).

Mas após um ano do evento ocorrido da Praça Espanha, no ano de 1987, foi apresentada uma carta protesto $^{4}$ escrita por Folco Portinari que institucionalizou o movimento Slow Food. No ano de 1989, diversos intelectuais de quinze países apoiam o manifesto e dissemina-se o movimento em um congresso realizado em Paris. Atualmente o movimento Slow Food encontra-se em mais de de cento e cinquenta paises espalhadas entre os cinco continentes. Também possui mais de centro e cinquenta mil associados. Isto sempre é narrado pelos participantes como um marco, uma revolução, uma mudança na estrutura "global" na sociedade contemporanea. Esta história é lembrada e reafirmada como um simbolo histórico de resistência, um processo de iniciação para o movimento, deve-se enterder o percurso e o Movimento como histórico e político.

O símbolo máximo do movimento, a carta protesto, que apesar de ser dirigida a Rede Fast Food, tem como objetivo não apenas alertar aos riscos da alimentação industrial contemporânea global, mas também enaltecer a busca do prazer alimentar (Andrew, 2010). Este prazer está vinculado ao produto local e tudo que a envolve, como por exemplo, as técnicas de fabricação, formas de consumo e preparo local. Diante disto, há o enaltecimento

\footnotetext{
${ }^{3}$ Enogastronomia é uma gastronomia que engloba a relação com a enologia, isto é algo voltado para a produção alimentar e para a produção de vinhos.

4 A 1 carta original pode ser acessada pelo link: http://slowfood.com/filemanager/Convivium\%20Leader\%20Area/Manifesto_ITA.pdf . Acessado em: 20/05/2016
} 
do elo entre natureza e cultura como pontos chaves para a obtenção do prazer. Indo contra alguns pensadores da mesma época, Petrini e seus compatriotas exaltam o prazer como elemento que originará a liberdade, isto é, o prazer como uma luta contra a homogeneização que era impulsionada pela globalização e um de seus símbolos o Fast Food.

Contudo, ao analisarmos o conceito de prazer e gosto o sociólogo Pierre Bourdieu (2006) diz que cada campo dentro de uma sociedade corresponde a um habitus, isto é, um sistema de dispositivos incorporados. Estes habitus particulares de cada campo geram uma distinção e assim uma variação de gostos. Enquanto para o Slow Food o prazer está direcionado a uma busca das minúcias dos sentidos sensoriais na comida local e alimentos da estação, para outros grupos que pertencem às classes diferentes o prazer está no ato de poder comprar um salgado tipo chips, por exemplo. Diante disto podemos inferir, a partir da teoria de Bourdieu, que o que ocorre com o advento dos Fast Foods e a relação com o prazer e o gosto não é uma homogeneização já que em uma única sociedade existem vários campos diferentes, que são como microcosmos que estruturam o espaço social, que contem regras e padrões específicos de cada grupo. Como notei nas ruas da Comunidade Chico Mendes, periferia de Florianópolis na parte continental, ao fazer um de meus trabalhos de campo. $\mathrm{O}$ bar que se localizava perto da escola, era frequentado por homens e mulheres comprando doces e salgadinhos industrializados para as crianças da família, ou da casa, após apreciarem a cerveja, industrial a base de milho transgênico, que bebiam para usufruírem o seu tempo não desprendido para o uso da sua força de trabalho e sim, para o que chamo de tempo de prazer.

Temos que levar em conta quando falamos de homogeneização alimentar o bio-psicosocial das sociedades/indivíduos. Pois o prazer/gosto pode ser analisado através de sua relação com a sociedade e a natureza. Isto é, toda cultura alimentar tem elementos, como matérias primas e técnicas de produção, oriundas de um meio ambiente local, assim produzindo uma cultura alimentar. Esta cultura, alimentar por sua vez, gera, para além de tabus (Douglas, 1966) também neofobia ${ }^{5}$. Estes elementos fazem com que, as redes internacionais de produção alimentar em grande escala, tenham que se adaptar a costumes e sabores locais (Fischler, 2006). Um exemplo comum é a adaptação de sanduiches da rede Mcdonalds para a cultura hindu, produzindo lanches vegetarianos e introduzindo condimentos como Curry. Isto é feito para não sofrer sansão ou poder viabilizar consumo.

Assim a relação entre prazer, natureza e cultura se liga diretamente com o consumo ao notar que a proposta de negação ao Fast Food não faz o Slow Food ter como intuito englobar-

\footnotetext{
${ }^{5}$ Rejeição a novos sabores.
} 
se a um movimento anticonsumista como os surgidos a partir dos anos de 1960. Ele se propõe a realizar um olhar voltado mais intensamente para o consumismo consciente, pois apresenta elementos discursivos acerca do "conheça quem planta, o que você come e compre com ele". Não enfrentando assim, diretamente a forma com que se estruturam os padrões econômicos e sim quer estabelecer uma reforma nestes padrões. Como coloca Fátima Portilho (2009) ao analisar os movimentos pró-consumo responsável como ampliadores da cidadania, em que o consumidor é um agente importante e decisivo para o mercado, que tem o poder e responsabilidade individual sobre o que consume. Mas o Slow Food ainda possui resquícios relacionados ao anticonsumo quando propõem novas formas de autonomia dos consumidores como hortas urbanas, consumos de xepas ${ }^{6}$ e da relação de não desperdício alimentar.

Os elementos que o movimento tem do anticonsumo esta ligado ao que o movimento chama de filosofia slow, ou seja, prezar pelo alimento "bom", "limpo" e "justo". Estes três elementos têm como perspectiva trazer um laço em que o bom seja ligado ao prazer, já dito anteriormente; limpo seja um alimento que esteja voltado a uma produção agroecológica e local, gerando menor deslocamento e necessidade de transporte de longas distâncias e prezando pela produção local; justo relacionado a questões de que todos dentro da cadeia produtiva e de consumo devem receber tanto economicamente quanto socialmente de forma equitativa.

Estes três elementos são a base estrutural do Slow Food, pois é na exaltação deles que se atingira um dos objetivos principais: o encurtamento da cadeia produtiva alimentar. Esse objetivo se liga diretamente em como os arranjos culturais moldam e são moldados pela natureza e o território na qual pertence. Busca-se utilizar ingredientes nativos da região, preferencialmente sem agrotóxicos ou substâncias químicas. A matéria-prima, em sua maioria, vem diretamente das mãos do agricultor para as mãos do cozinheiro, chefe de cozinha, ou se não for possível, busca-se pelo menos minimizar a trajetória do alimento ${ }^{7}$ para que haja a consciência da origem do produto que se consome (Petrini, 2009). Isto, no entanto, não significa que ao encurtar esta cadeia as redes de relações estabelecidas irão ser mais simples.

A internacionalização do movimento e a visão do afastamento produtivo está diretamente relacionada à globalização contemporânea. Para Ulrich Beck (1999), a

\footnotetext{
${ }^{6}$ Xepas são produtos alimentares que tem potencial de consumo e são descartados em decorrência de falas, imperfeições e certas danificações ocasionadas pelo transporte o ao serem colhidos.
} 
globalização na sua estrutura atual tem como um de seus marcos a queda do muro de Berlim no ano de 1989. Este estopim gerou uma mudança no processo modernizador com relação à economia, ao mercado e à política. Para o autor a globalização ${ }^{8}$ pode ser entendida como sendo “os processos em cujo andamento os Estados nacionais veem a sua soberania, sua identidade, suas redes de comunicação, suas chances de poder e suas orientações sofrerem a interferência cruzada de atores transnacionais." (BECK, 1999: 30). Estes processos são consequências do que chama de globalidade. Para o autor, a primeira modernização se deu com a revolução industrial e a sociedade de massa. Neste momento a família era o centro da estrutura sociocultural. Já a Modernidade reflexiva, ou segunda modernidade, é oriunda do processo de globalização, e a individualização torna-se o centro estrutural da sociedade.

$\mathrm{O}$ afastamento entre produtores e consumidores, e o que chamam da grande cadeia produtiva alimentar, surgida em decorrência desta globalização, é visto como processo homogeneizador, fazendo com que haja uma perda de identidade da comida e da alimentação. Pude perceber isto através de várias falas dos participantes ao levantarem questões sobre o resgate de alimentos nativos. Estes alimentos nativos são considerados os alimentos endêmicos, isto é que fazem parte da fauna e flora local, ou que foram produzidos socialmente e historicamente marcando uma localidade. Como a fala uma interlocutora moradora de Pirenópolis e dona de uma fazenda ao se referir ao resgate que realizou de uma receita de matula ${ }^{9}$ com uma senhora moradora de uma casa de idosos.

Ao realizarmos o encurtamento da cadeia produtiva nos aproximamos cada vez mais como os produtores, do que comemos e com o meio ambiente na qual pertencemos e da origem do que comemos. Com isso podemos apresentar uma crítica tratada pelo movimento Slow Food que é oriunda da visão sobre o fortalecimento dos saberes e técnicas locais de produção, e também dos produtos nativos. A consequência deste encurtamento, entre outras coisas, seria o conhecimento do que estamos comendo. E ao resgatarmos essa identidade alimentar perdida com a grade cadeia, podemos obsevar o que Maria Eunice Maciel (2001) levanta sobre a comida como um potencial marcador territorial e que assim serve como marcador identitário ligado a uma teia de significados sendo assim possível que haja sistemas

\footnotetext{
${ }^{7}$ Uso o termo Alimento como proposto por DaMatta (1987) que vê como sendo apenas um elemento nutricional que nos permite sobreviver, comparando-o a uma moldura. Enquanto comida é um elemento que além de nutrir é socialmente aceito e que dá prazer e é torna-se um marcador identitário.

${ }^{8}$ Ele opõe ao conceito de globalização e globalidade ao conceito de globalismo. Que seria um conceito voltado às questões mercadológicas e ao mercado. Globalismo sobjulgaria a ação política e social a meros fantoches do mercado. Chama de ideologia do império do mercado mundial ou do neoliberalismo.

${ }^{9}$ Matula é equivalente a marmita, ou comida para viagens. Isto vem com a tradição dos viajantes e tropeiros no período colonial brasileiro.
} 
alimentares delimitados como podendo existir a "cozinha sertaneja", "cozinha brasileira". Cria-se assim uma distinção social através do que se come.

Em virtude da busca por um retorno ou marcador desta identidade culinária e alimentar, indo na contracorrente desta individualização global trazida por Beck (1991), o Slow Food acaba se diferenciando em cada um dos mais de cento e cinquenta países em que está inserido e ainda em cada região destes países. Para demonstrar como os locais se interconectam e se diferenciam entre si, trago em seguida um pouco da construção brasileira do movimento e da minha vivencia de campo entre os participantes do grupo local do Slow Food em Florianópolis. Estes grupos são chamados de Convívios, e o que frequentei era denominado de Mata Atlântica.

\section{O BRASIL UM GRANDE ESPAÇO NATURALMENTE “GOURMET”}

Ao iniciarmos nossa viagem, indo do contexto global para o local, iniciarei trazendo uma visão de globalização, mais especificamente de fluxos alimentares globais estudada por Viviane Assunção (2012) com os migrantes brasileiros em Boston, nos Estados Unidos da América, e como ocorrem os fluxos e redes alimentares percebeu a valorização que se tem com relação à alimentação nacional e como ela é um marcador identitário e de memória familiar. Assunção (2012) mostra como a roça e os produtos regionais são elementos que estão fortemente na memória destes migrantes que levam para Boston ou pedem para quem for visitar levar. Apesar de não estar me atendo em migrantes geográficos pude perceber esse elo com o local por meio de relatos dos membros do Slow Food que, como se fossem migrantes temporais imaginários, veem o movimento como uma busca de alimentação que chamaram "dos avós", isto é, por em prática algo que está na memória alimentar, em sua maioria de origem rural, em que o produto consumido era o que vira plantar e crescer. Este movimento no tempo por vezes inclui movimentos no espaço. Como quando um dos membros me mostrou vídeos da viagem que fez a sua família no interior, no qual aparece fazendo morcilha ${ }^{10}$ e torresmo ${ }^{11}$ com seus familiares após matarem o porco da fazenda, me

\footnotetext{
${ }^{10}$ Tripa de porco recheada com o sangue e os miúdos do animal. Utilizam-se tanto o que chamam de tripa grossa como tripa fina.

11 Torresmo é naco (pedaços) de carne de porco, em geral as que possuem mais gordura, fritas na gordura do animal. No caso citado foi feito com fogo de chão em que os utensílios ficam suspensos e o produto é frito na própria banha em prensado para que se tire um pouco da gordura. Falo da forma com que foi feito, pois para eles o processo de produção é significativo, já que remete a um fazer tradicional. Como o Doce de leite feito no tacho de cobre.
} 
contando que passou sua infância neste lugar e que todos deveriam poder ter um contato tão próximo com o que vão comer.

Mas o movimento Slow Food apesar de sua abordagem internacional e oriunda, como já exposto anteriormente, do velho mundo se configura de forma localizada e para isso tem que aceitar e garantir as peculiaridades de cada território no qual se insere e é inserido. Pois como Viviane em Boston, podemos perceber que não há como criar uma produção lá com técnicas e alimentos oriundos do Brasil.

No Brasil, por exemplo, entre outras coisas, a própria estrutura interna se diferencia dos demais países, por sua grande espacialidade e força. Logo o Brasil conjuntamente com mais nove países que são eles Alemanha, Suíça, Estados Unidos da América, Japão, GrãBretanha, Holanda, Quênia, Coréia do Sul e a Itália fazem parte de uma que se aproxima de uma autárquica, ou seja, apesar de ainda ligada a sede italiana e ter que responder a certas atitudes, regras e compromissos tem limitada autonomia financeira e política, assim o país possui o "selo" Slow Food Brasil.

Diante disto, uma das ações estruturais do movimento se diferenciou. Sendo criado, os chamados Facilitares Regionais, que seriam membros associados ao movimento de cada região do Brasil (Sul, Sudeste, Centro-Oeste, Norte, Nordeste) que representariam esta região levando demandas e particularidades de sua região e fazendo "nós'12 com as redes locais e estaduais, regionais e levando isto para a organização nacional. Esta divisão apriori seria pela divisão de biomas brasileiros, abarcando melhor a proposta de simbiose entre meio ambiente e sociedade por meio da alimentação. Contudo esta divisão ultrapassa os Estados e assim faz com que ocorram impasses políticos.

Para demonstrar essa simbiose vou trazer um pouco de uma experiência do meu trabalho de campo que se deu por meio de uma viagem com os participantes do Mata Atlântica chamada de projeto expedições realizada na região do Planalto Central buscando os sabores do cerrado, no ano de 2015. Contudo por eu ter viajado com três participantes que haviam ido para a região do Marajó, em outra viagem do mesmo projeto, muitas histórias foram contadas e assim momentos de comparação poderão surgir. Este projeto intuito expedição realizado pelo "Convívio" Mata Atlântica tem como objetivo de realizar viagens nos seis biomas brasileiros: Amazônia, Caatinga, Pantanal, Cerrado, Mata Atlântica e

\footnotetext{
12 "Nós" é um termo usado pelos participantes do movimento que significa elo ou ligação, muito próxima a ideia
} de Manuel Castells (1999) e os nós da rede. 
Pampa $^{13}$ para conhecer a fauna e flora das regiões e suas utilizações na gastronomia conjuntamente com as práticas e técnicas utilizada para produção das "gastronomias regionais".

A viagem junto ao projeto expedições teve uma duração de dez dias sendo percorridas sete cidades diferentes: Brasília; Pirenópolis; Goiânia; Alto Paraíso, São Jorge; Cavalcante e Sobradinho (cidade satélite de Brasília). Viajamos de carro em cinco pessoas conhecendo comunidades; indústria; comércio e produtores da região. Tentamos abarcar as variadas linhas de o processo alimentar, ou como diria Goody (1998), o processo total de produção, preparação e consumo. Apesar de termos frequentado espaços de produção, preparação e consumo variados e que abarcavam produtos diversos o Baru ${ }^{14}$ acabou por ser nosso principal personagem, ele estava de certa forma, em quase todos os locais que visitamos.

Como já mencionado anteriormente, os biomas não delimitam as fronteiras dos estados brasileiros, por isto nas expedições cruzamos estados, como na minha viagem que frequentamos Distrito Federal e Goiânia. Contudo, mesmo estabelecendo fronteiras baseadas em biomas estas não sanem algumas dificuldades de classificação que se pode observar no contato com o meio ambiente em si, como através dos discursos comparativos com a expedição anterior. Os motivos que me levaram a levantar essas dificuldades foram à sobreposição dos biomas e as diferenciadas formas de utilização da fauna e flora pelas variadas identidades pessoais e alimentares, fazendo com que não se possa estabelecer uma correlação direta entre bioma e prática alimentar específica, sendo essas práticas múltiplas.

Ao analisarmos a sobreposição dos biomas propõe-se que não há uma ruptura que estabeleça uma mudança clara entre eles, uma fronteira definida. $\mathrm{O}$ que existe em um bioma pode estar presente em outro e continuar sendo um produto "endêmico" de ambos os biomas. Isto pode ser percebido pelo discurso de uma pessoa do cerrado que trouxe a seguinte fala:

A Amazônia tem a fama. É a bola da vez. Mas na verdade muito da vegetação que é marcada como sendo da Amazônia na verdade é do Cerrado. Ou melhor, é também do cerrado. Às vezes fico me perguntando. Recebi a notícia de que havia sido

\footnotetext{
13 Trago esta divisão que é estabelecida através do Instituto de Geografia e Estatística (IBGE). Contudo esta divisão não possui consenso. Há pesquisas que trazem o manguezal como um bioma a parte e ainda há outros que incluem um oitavo que seriam as zonas de cocais. E ainda existe o bioma marinho que é a Zona costeira Brasileira e que se mescla com a vegetação dos manguezais. E há outras divisões que podem ser vistas através dos vários mapas presenteados. O que mostra uma fragmentação cada vez maior através de reclassificações. Mudanças tais que podem ser atribuídas as mudanças que o correm com o meio ambiente e que não necessariamente seja apenas pelos impactos humanos, mas pela própria interação do meio ambiente com os demais meio-ambientes.

14 Baru é uma castanha oriunda do cerrado brasileiro, em que sua forma de produção está pautada do extrativismo da castanha que cai do pé do barueiro.
} 
encontrada uma espécie de árvore nativa do planalto central lá no meio da Amazônia num lugar bem longe e inóspito. Isso não é coisa só do homem não as coisas e plantas também caminham, como nós. Tudo anda até mesmo as coisas que tem raiz. Achei engraçado quando me vi pensando nisso. Além do mais, às vezes a gente se acha muito importante né, poderoso. Só nós temos o poder de destruir, mudar, alterar, controlar. E na verdade somos mais um no meio, esquecemos que somos animais também.

Quando mergulhamos neste discurso podemos nos deparar com um conflito entre pessoas e a sua apropriação com relação ao bioma. As comidas caminham, lembrando que este caminhar não apenas pela propagação produzida pelo ser humano. Mas também caminham através de elementos que fazem parte da natureza, como os pássaros, o vento, os animais de modo geral. Balée (1993) traz essa visão de tempo e modificação dos espaços naturais e da relação com a biodiversidade comparativamente entre as Sociedades-Estado dependentes do combustível fóssil e as sociedades Indígenas pautadas na caça-coleta e horticultura. Mostra que não é o ser humano o causador de modificações negativas no meio ambiente, mas sim suas ações e a forma exploradora que algumas sociedades se relacionam com o meio.

Por questões de diferentes apropriações dos biomas por coletivos distintos. Como mostra uma de minhas interlocutoras ao apresentar a história do empadão goiano, comida típica e muito presente em todas as padarias e bares que estivemos. Esta interlocutora ressalta ao longo da conversa que este prato é um exemplar adaptativo surgido em decorrência da migração transoceânica e das trocas alimentares que ocorreram entre os colonizadores e os colonizados, isto é, portugueses e brasileiros.

\begin{abstract}
Ai você começa a ver as adaptações da gastronomia. Por que no nosso empadão goiano a gente usa aquela coisa 'malcoza' que é a gueroba. Que vocês conhecem, já ouviram falar. Guariroba. Que a guabiroba é uma fruta do cerrado também, deliciosa. É guariroba que é aquele coqueiro ali. Porque que nós usamos de repente, ai você pergunta, - mas Dona porque goiano adora essas coisas amargas? - Não é que a gente adora não, é que a gente não tinha outro. Porque a sua comida depende do seu bioma. O Brasil tem 6 biomas. Então o nosso bioma do cerrado, nós não temos palmito. - Há! Vamos fazer uma torta? Vamos. É que o empadão é uma herança que nós tivemos das portuguesas, dos pastelões. De repente uma portuguesa - vamos fazer uma torta! A! Mas cadê o palmito? - Goiás não tem. Aí resolveram usa o palmito, esse nosso palmito que é super amargo. Que é a guariroba. Então por isso que o nosso empadão tem essa coisa que é amarga. Que é o nosso palmito do cerrado, podemos dizer assim. Então você vai vendo as adaptações. (Grifos meus)
\end{abstract}

Ao finalizar a conversa ela traz uma relação interna de traços inter-regionais a forte necessidade de identificação e diferenciação de técnicas de preparo do pão de queijo entre goianos e mineiros e a utilização do Pequi que é quase ausente na culinária mineira. Esta 
necessidade que tem de diferenciação é feita pela alta aproximação que se tem da alimentação destes dois Estados. Ambos não possuem saída para o mar (juntamente com Tocantins) e tiveram uma história alimentar próxima com alta produção de queijo e uso da farinha de mandioca (entre elas destaca-se o polvilho) e a relação com os viajantes e tropeiros e para finalizar por serem dois Estados que compartilham do mesmo bioma. Esta disputa alimentar permite-nos notar um discurso conflituoso entre goianos e seus vizinhos mineiros. Este conflito visto como um conceito que não deriva apenas de um ponto de vista negativo e violento da sociedade, ele é constituidor da sociação o conflito como união e desunião como nos afirma George Simmel (1983):

\begin{abstract}
O próprio conflito resolve tensões entre contrastes o fato de almejar a paz é só uma das expressões - e especialmente óbvia - de sua natureza: a síntese de elementos que trabalham juntos, tanto um contra o outro, quanto um para o outro. Essa natureza aparece de modo mais claro quando se compreende que ambas as formas de relação - a antipatia e a divergente - são fundamentalmente diferentes da mera indiferença entre dos ou mais indivíduos ou grupos. Caso implique na rejeição ou no fim da sociação, a indiferença é meramente negativa; em contraste com essa negatividade pura, o conflito contém algo positivo. Todavia seus aspectos positivos e negativos estão integrados; podem ser separados conceitualmente, mas não empiricamente (SIMMEL, 1983; p. 123)
\end{abstract}

Isto se dá por ela ver uma invisibilidade de Goiás em detrimento de Minas Gerais que acaba sendo identificado por muitos alimentos comuns como doce de leite, cachaça, queijo de leite cru e pão de queijo. Mas ao mesmo tempo destaca que esta importância foi muito proveitosa para Goiás, pois assim pode-se perceber que o Estado marcou mais suas raízes.

Mas não foi apenas a viagem que me forneceu subsídios para a análise sobre a relação entre alimentação e ecologia. Em Florianópolis pude vivenciar um evento que almejava conscientizar a população sobre o desperdício alimentar, chamado Disco Xepa. Para a realização do evento fomos buscar alimentos em feiras, supermercados e vendas que seriam descartados por suas aparências, manchas e machucados, mas que ainda possuem potencial alimentício e se faz uma festa em que a comida é feita com estas matérias primas. Foram feitas três edições, contudo na segunda, realizada em uma comunidade de periferia da cidade de Florianópolis, foi realizada em parceria com um grupo da cidade chamado Revolução dos Baldinhos que tem como objetivo realizar uma compostagem comunitária para que o lixo não seja descartado incorretamente e a comunidade reduza os índices de doenças.

Assim neste evento vimos claramente o ciclo completo dos alimentos, indo falar com produtores nas feiras para utilizar os alimentos que iriam descartas, passando pela produção 
dos pratos que seriam servidos, chegando a compostagem com os orgânicos que foram descartados e novamente abrindo o ciclo com pessoas buscando o adubo para suas hortas. Este evento mostrou que a relação do homem e a natureza através da produção alimentar, não se encontra apenas isolada nas comunidades tradicionais ou nos campos agrícolas, também pode ser claramente observado dentro das cidades.

\section{O QUE A COMIDA TEM HAVER COM ECOLOGIA?}

Entre muitos assuntos que envolveram meus dezoito meses em campo uma delas foi à educação. O que me possibilitou abrir espaço para pensar sobre a relação que é feita entre educação - cotidiano - alimentação - meio ambiente. Mais precisamente esta ligação se deu com a fala que se fazia muito presente entre vários participantes: "é a partir dela [educação] que podemos estabelecer uma mudança no cotidiano, na alimentação e assim realizar uma mudança estrutural, a partir do alimento que envolve todo o ecossistema.”. Esta colocação que estava presente em vários depoimentos de participantes do grupo vincula-se ao que Carlo Petrini propõe com a nova gastronomia, ou a chamada ecogastronomia:

\footnotetext{
Este é o desafio da nova gastronomia: sistemas educativos permanentes para todas as idades e para todos; para as crianças, que têm o direito de aprender como os sentidos devem ser usados, como a comida é produzida, de onde provém; para os pais e professores que não têm mais condições de educar para o alimento para o alimento; para os "consumidores" - e estamos prontos para discutir esse termo -, que podem escolher o melhor; para os produtores e os operadores do mundo do alimento, que querem potencializar seu profissionalismo; e para os idoses, desconfortáveis num mundo em rápida mudança. (PETRINI; 2009, p. 146-7)
}

O termo ecogastronomia foi implantado para definir uma gastronomia baseada não apenas numa crítica ao consumo sem vínculo com o seu preparo. Mas traz consigo a importância do conhecimento e contado com o meio socio-ecológico em que o alimento que será transformado em diversos pratos e saboreado está inserido, para assim ter o conhecimento de como e onde são produzidos e por quem. Saber disto é aproximar-se do produto e criar relações sociais através do que, por fim, ira "tornar-se você". Isto pode ser visto na explicação de um interlocutor, agrônomo que trabalha em um centro que desenvolve trabalhos com foco nas questões rurais e de desenvolvimento sustentável, como hortas urbanas na cidade de Florianópolis: 
Mostrar que este alimento depois ele não é lixo ele é uma matéria prima de excelente qualidade. O que faz perder o valor é a forma com que a gente se dá com ele. Às vezes de colocar num saco e misturar tudo. A gente cria essa aparência "feia" para esse material. Mas a gente sempre fala uma casca de laranja assim que tu descasca ela é cheirosa e ela e linda. Então se tu já dá um encaminhamento para isso tu estas trabalhando com uma matéria prima de excelente qualidade. E outra questão da revolução está no prato é que quando a gente opta por um alimento ecológico a gente esta compartilhando toda uma energia que vem desde o produtor. A gente está incentivando que ele continue tendo essa relação com a terra. E quando a gente opta por um alimento e nem tem relação, o alimenta da agricultura convencional, um alimento todo processado, em fim todo artificial tu tá alimentando tanto essa cadeia de produtos como a energia que tu estás consumindo. O que a gente vê é que se a gente trabalha com um alimento que tem uma energia muito maior a tua saúde vai ser muito maior, tu estás estimulando toda uma saúde dessas pessoas e até contribuindo para que outras pessoas entrem nesse movimento. Que é um movimento mais local, trabalha com relações, trabalha com pessoas, o prazo de validade é menor, vendo assim que a vida está no alimento.

Este conceito nos mostra que a ideia de ecologia não é apenas uma disciplina isolada e operada pela biologia em que o homem não está presente ou apenas é mais um na bioesfera. $\mathrm{E}$ sim requer um pensamento transdisciplinar que envolve todas as áreas de conhecimento e que o homem é agente modificador e modificado pelos meio-ambientes e o ecossistema que está inserido.

Antes de mim, muitos autores começaram a se questionar sobre isto, nascendo à ecologia social, ecologia humana entre outras. Mas, além disto, como Paulo Henrique Freire Vieira (1995) propõe, ao estudar o ecodesenvolvimento, que o ser humano também está inserido em uma ecologia, debruçando-se no conceito de Noosfera para determinar que nossa subjetividade também não escapa da ecologia e da "natureza" (pensando como meio ambiente) que estamos inseridos, indo além do ser humano como modificado e modificador do meio como sujeito histórico, mas também busca no inconsciente ou na subjetividade, através do olhar que temos do mundo e sobre o mundo.

Anna Tsing (2015) retoma este pensamento trazendo a relação entre as mulheres e os cogumelos através da história e do um novo olhar sobre o conceito de etnografia interespécies e domesticação, que é um conceito diretamente ligado à ideia de relação entre ser humano e a modificação do meio. Contudo a autora trás um novo olhar propondo que esta modificação é recíproca, pois enquanto o ser humano domestica as outras espécies, como plantas, fungos e outros animais, estes também domesticam o ser humano.

É com base nesses dois olhares que pretendo analisar este conceito do ecogastronomia. Pois aqui podemos ver que no entendimento dos participantes do Slow Food a gastronomia como consumo final não tem sentido se não estiver interligada com seu meio ambiente e com a produção através deste meio ambiente. Ao pregarem por uma alimentação em que a produção seja local, as plantas e animais sejam endêmicos ao meio, se não que pelo menos estejam historicamente adaptados a este espaço sofrendo modificações e se adaptando ao 
novo espaço, como o empadão goiano ou os vinhos da serra gaucha e catarinense. Isto mostra como o ser humano também busca adaptar-se e permite se modificar para pertencer, conviver e estar em seu meio.

No ano de 2014, em decorrência dessa forte demanda com relação à alimentação, no Brasil aconteceu uma grande campanha para entrar em votação um projeto propondo uma inclusão na Lei Rouanet (Lei $\mathrm{n}^{\circ}$ 8.313, de 23 de dezembro de 1991) que considerasse a gastronomia como cultura. Este projeto é o Projeto de Lei 6562/13. Um dos principais aliados deste projeto é o cozinheiro Alex Atala por meio do instituto que fundou chamado ATÁ ${ }^{15}$ e um dos nomes nacionais que participam e apoiam o movimento Slow Food. Este movimento estava muito presente nas redes sociais com a marca \#EuComoCultura e \#GastronomiaEhCultura acompanhavam muitas fotos em que as pessoas seguram um prato com a frase "eu como cultura". Estas fotos eram acompanhadas pela comida brasileira preferida da pessoa que estava apresentando o prato.

A comida hegemônica atual é vista pelo movimento como a base da destruição do meio ambiente, em especial a produção baseada em monocultora, e as que envolvem tecnologias como OGMs e Transgênicos. O que remete ao que me foi levantado por uma interlocutora paraense, quando me apresentei como antropóloga na viagem que fizemos para Alto Paraíso, sobre a oposição entre gastronomia e cultura alimentar.

Nós estamos fazendo uma campanha para alterar lei Rouanet. Porque daí nós podemos marcar bem uma diferença difícil de ser entendida que é a gastronomia. Tudo o que comemos pode ser associado à gastronomia. O hambúrguer do McDonalds é gastronomia. Agora ser cultura alimentar aaa isso não hem. Por isso acho legal reforçarmos, pois a cultura alimentar tem uma prática local, uma tradição que a envolve, um povo que a produz, é local é pessoalizado. É uma comida que identifica uma comunidade, um povo, uma cultura.

Através da fala de uma interlocutora marajoara ${ }^{16}$ que possui um restaurante e possui um instituto que promove a preservação e valorização da cultura dos povos locais, podemos perceber que a gastronomia e a cultura alimentar são elementos que se unem por meio de uma concepção de comida como nutricional, mas que divergem quando se chega à relação entre produção e consumo, como Daniel Miller (2007) escreve sobre os bens materiais. Assim o

\footnotetext{
${ }^{15} \mathrm{O}$ instituto ATÁ é um instituto fundado em 2013, tendo como principal fundador o Alex Atala. Tem como um dos principais objetivos valorizar a cultura alimentar amazônica.

${ }^{16}$ Localizados no norte do Brasil, se concentrando mais no estado do Pará, em que há uma região que leva o nome arquipélago do Marajó. A Amazônia marajoara é formada a partir de um contato inter-étnico entre os
} 
autor aponta que a maioria dos movimentos ambientalistas e outros baseados numa perspectiva de anticonsumo, incluindo o Slow Food, tem a tendência a trazer apenas o lado negativo do consumo, enquanto meio de alienar e de controlar, gerando fetichismo. Criandose assim uma oposição: consumo material e consumo simbólico, negando uma coexistência entre eles e ainda mais, criando um juízo moral que culpabiliza o consumidor. A produção é posta em segundo plano nas análises. Apesar de concordar com o autor, verifiquei que o Movimento Slow Food traz o produtor à tona.

com respeito à crítica ambientalista contemporânea, a mesma perspectiva moral se tornou arraigada num viés semântico onde o consumo é novamente sinônimo de destruição. Por exemplo, a crítica ambientalista poderia ter sido em grande parte dirigida à destruição dos recursos do mundo associados com a produção, tal como o impacto da indústria pesada ou da agroindústria ao invés do consumo. Mas não é isso o que acontece. A destruição é primeiramente identificada com a postura própria do consumo, com o consumidor visto como gastando recursos escassos ou insubstituíveis, e a produção nessa instância é vista como auxiliar secundário ao consumo. (MILLER, 2007: 35)

Outro fato que me foi apresentado ao questioná-los sobre a ecogastronomia está relacionado ao consumo de carne. O movimento não estabelecer uma relação direta com movimentos vegetarianos e veganos, contudo possuem vínculos e preceitos que se intersectam com a luta destes movimentos vegetarianos e veganos. Pois a relação homem animal apenas baseada no utilitarismo como era visto por Marvin Harris (1978) não se sustenta mais. Cria-se um elo entre homem e animal em especial a partir de uma ligação social e vinculo de aproximação. Isto é demonstrado por Marshall Sahlins (2003) ao apresentar uma repulsa a comer certos alimentos que nos assemelham, como ocorre com os órgãos, sendo a carne mais consumida em sua forma assada ou cozida de forma que descaracterize essa imagem próxima a um $E u$. Assim, o sofrimento e a tortura dos animais tomam um destaque importante, sendo um dos principais pontos que é abordado por Atala e o Movimento Slow Food. Em uma entrevista em abril de 2013, ano de abertura do instituto, para Débora Spitzcovsky jornalista do Planeta Sustentável, Atala, traz a questão da carne entre outros tópicos igualmente importante para o Slow Food:

- Retratos do Gosto, que busca aproximar chefs e produtores em prol do uso de
ingredientes mais sustentáveis com alto potencial gastronômico;
- Servir Insetos, que incentiva o uso de insetos como a formiga saúva amazônica nas

colonizadores, indígenas e africanos. Cria-se assim uma cultura afro-indígena. Sendo a arte material muito marcada pela cerâmica, alimentos e o bordado. 
receitas

culinárias;

- Pimenta Baniwa Jiquitaia, que procura introduzir no mercado a pimenta produzida pelas mulheres da tribo indígena Baniwa e - Carne Sustentável, que defende o uso da carne produzida de forma sustentável. (SPITZCOVSKY, 2013)

Para o movimento o ato de comer carne/comer animais não apresenta apenas problemas que circundam de relação econômica. O problema que mais comentam está direcionado as questões de tratamento e condições de vida que os animais permaneceram até a sua morte e a forma com que se estabelecem mecanismos industriais com relação aos outros seres. Como muitos aviários que são montados por industriais que produzem animais bombeando luz a cada período e injetando hormônios para que cresçam rapidamente. Bois produzidos em espaços pequenos sem terem contato com a luz do sol. Vacas que tem suas mamas flageladas por maquinários que retiram leite. Utilizo o termo produzir, pois vários participantes do movimento usam este termo para identificar a pecuária e criação de animais para consumo alimentar com uma forma intensiva e de apelo industrial, trazendo-os como produtos e não mais criação, trazendo uma desvinculação e interação entre animais, e sim como bens a serem preparados para consumo. Sobre isto uma interlocutora moradora de Pirenópolis dona de uma fazenda tradicional comenta:

Se você vê o abate você quer morrer. Ele é um produto, tanto é que eu vi separando os pintinhos. Tem uma esteira jogando os pintinhos amontoados e selecionando os pintinhos. Os que não vão ser usados, que é fêmea, vão amontoando em um latão. Eu vejo um animal como um animal, que tem dor. Mas eu abato. Abato para comer. Mas isso exige respeito que eu aprendi com minha mãe. Minha mãe dizia - hó! Não fica com pena de mais não, se não, não morre. - Porque quanto mais pena você tem dó, parece que demora mais para morrer. Minha mãe dizia para não ter dó não. Que aí é que ele sofrendo. Aí a gente não deve ter muita dó.

A ecogastronomia tornou-se uma forte bandeira do Movimento Slow Food chegando a criar um Slogan de luta chamado “A Revolução está no Prato". O objetivo é mostrar que a luta para uma mudança na econômica, política, social, isto é, uma mudança estrutural está na cadeia produtiva e no consumo de alimentos. O Slow Food foi uma das redes precursoras, na contemporaneidade, a trazer e dar destaque a importância política que o alimento e seus processos possuem. Sendo assim o garfo e a faca como as principais "armas" para começar a revolução. Ou melhor, a partir do alimento teremos a faca e o queijo na mão para realizar a revolução. Quando perguntei para um interlocutor de Florianópolis e cozinheiro formado em 
gastronomia sobre o Slogan revolução está no prato à resposta que recebi foi associando ao projeto Disco Xepa:

\begin{abstract}
Porque quando a gente come a gente não imagina da onde veio o nosso alimento ser humano acabou se distanciando do processo natural de contato com a cadeia produtiva do alimento e o desperdício de alimento é um caso muito sério que atinge as diferentes camadas da sociedade. Quando a gente se alimenta acabamos deixando um pouquinho de resíduos no prato e para onde vai esses resíduos, o que acontecem com esses resíduos que são desperdiçados? Esses resíduos na maior parte das vezes acabam indo para um aterro sanitário. E no caso do projeto revolução dos baldinhos eles aproveitam todos esses resíduos. Fazem o aproveitamento integral desses alimentos. Então eu acho que essa Revolução mesmo que tá no prato, ela começa no prato, mas tem todo um processo que envolve. Desde o começo até o final da cadeia produtiva, quando é produzido até o descarte desses resíduos. Que a gente se dá conta através da nossa alimentação no dia-a-dia.
\end{abstract}

Para estabelecer uma prática com relação à Revolução está no Prato foi criado na Inglaterra o Food Revolucion Day, que marca a importância do tempo para essa revolução. O movimento de mudança deve acontecer o mais rápido possível, contudo é necessário que não se esqueçamos de que a lentidão é a base para esta mudança, assim prioriza-se a revolução cotidiana. Diante disso, criou-se um dia para que fosse aberto debates, discussões e é claro “comensalidade Slow". Um dos principais nomes envolvido neste movimento é o cozinheiro Jamie Oliver, que também é participante do movimento Slow Food. E seu principal foco se volta para a prática da educação alimentar escolar.

O motim que possibilitou a criação de tal movimento está estruturado no crescimento da obesidade na população mundial e em especial na infância que é vista como uma das psicopatologias da alimentação cotidiana, juntamente como vigorexia, anorexia, bulimia, como traz Claude Fischler (2006). O autor sempre leva em conta as questões sociohistóricas do imaginário corporal ressaltando que a visão de um corpo saudável em várias épocas e locais difere, mas que hoje com as questões industriais e tecnologias os riscos estão se apresentando com mais elevado grau e a consequência é o sobrepeso. E faz um comparativo entre Estado Unidos e França:

É muito fácil compreender a conexão entre o controle interno ou externo e a obesidade.

Nos Estados Unidos, por exemplo, como consequência da ideia de que existe uma responsabilidade individual pelo ato de comer, eles também são responsáveis por comer aquilo que não poderiam ou não deveriam comer, o que pode causar doenças, o que pode engordar, o que pode torná-los obesos. Eles, como únicos responsáveis pelo que escolhem comer, deveriam comer corretamente, alimentos saudáveis, que não engordassem. Deveriam fazer as escolhas certas. Deveriam controlar o que comem. 
Mas, como é óbvio ao se olhar o porcentual de indivíduos obesos ou gordos nos Estados Unidos, eles não conseguem ter competência para decidir o que deveriam comer. Os Estados Unidos têm a taxa mais elevada de obesidade no mundo. Os americanos não têm controle sobre o que deveriam comer. Eles engordam, têm diabetes, problemas cardiovasculares, etc.

Na França não se vê pessoas comendo na rua, não se vê motoristas de táxi dirigindo e comendo, não se vê pessoas no metrô comendo. Se por acaso alguém faz isso, é quase chocante. Existe uma rejeição enorme. Imediatamente pensam que não é um francês, que é um turista ou alguém de fora. $O$ francês iria se sentir constrangido pelo olhar dos outros, seria uma situação muito desagradável. A regra não é dita, pois não precisa ser dita. Simplesmente, na França, não faz sentido alguém comer na rua ou no metrô, comer e fazer alguma coisa diferente ao mesmo tempo. Faz parte da nossa cultura, não é algo que precisa ser dito aos franceses. Seria muito estranho, para nós, comer dessa forma. (GOLDENBERG entrevista Fischler, 2011: 246-7).

Embora os tempos recentes tenham desmentido, em parte, Fischler e se veja franceses comendo na rua, seu número ainda é bem menor do que o dos norte-americanos. Esta discussão sobre obesidade é muito frequente nos encontros nacionais e internacionais do movimento Slow Food. Podemos ver através do discurso feito por Jamie Oliver, no TED $\mathrm{X}^{17}$ "My wish is to create a strong sustainable movement to educate every child about food, inspire families to cook again and empower people everywhere to fight obesity.". Um filme documental que retrata de forma explicita as consequências e problemas causados por este transtorno no Brasil é Muito além do peso Dirigido por Estela Renner (2012).

Diante disto o Slow Food compartilhando da perspectiva do escritor e jornalista Michael Pollan no livro Cozinhar - Uma história natural da transformação publicado em 2014 vê o preparo da comida além das tabelas nutricionais, mostrando a importância política de se fazer e preparar o que se come, pois isto gera independência e autonomia. Propõe assim que a comida é um ato revolucionário. Pois ao fazer o que comemos ou termos conhecimento das suas origens começamos a ter mais proximidade com o alimento e assim conhecemos mais o que usamos para comer. Pollan crítica a monocultura extensiva e intensiva e a pecuária baseada em maus tratos animais. Esta crítica vem também na direção do que o movimento Slow Food anda indagando sobre a midialização dos chefes de cozinha através de programas de televisão e revistas especializadas. Não que achem isto algo ruim, apenas dever-se-ia trazer a tona como protagonistas os produtores e trabalhadores da terra. Assim o Slow Food começou a apoiar e compartilhar o Slogan "Cozinhar é um ato revolucionário".

Apesar de quererem diminuir a cadeia produtiva, os participantes do Slow Food não necessariamente se neguem a criação de tecnologias e questões industriais. O que discutem, em suma, é a relação de afastamento e do conhecimento do produto e o protagonismo de

\footnotetext{
${ }^{17}$ Ver palestra completa em https://www.youtube.com/watch?v=wOP18P2S-Lw Acessado em 20/10/2015.
} 
quem produz o alimento. Como quando visitei uma indústria de frutas desidratadas em Pirenópolis, em que há uma constante tentativa de não haver desperdício e sempre pensam na melhor maneira de aproveitar as frutas e o contato com os produtores é direto, inclusive viajam para conhecer estes fornecedores. Neste momento do trabalho de campo que realizei percebi a relevância da tecnologia para que haja melhores mecanismos para desenvolver produtos com uma pauta ecológica. Inclusive as máquinas que criaram foram desenvolvidas em parceria dos donos com engenheiros. A meta proposta é chegar a 100\% da utilização das frutas. Um exemplo de que esta busca não é utópica é a maça que sobra apenas o pequeno talo que a ligava ao tronco da árvore, como trás um participante morador da cidade de Pirenópolis (GO) e Biólogo:

\begin{abstract}
A busca é sempre ter o mínimo desperdício na produção até o liquido da fruta é utilizado e as maquinas de descasar que são programadas para o menos desperdício, e os trabalhadores que cortam a manga (uma das únicas que precisa ser manual, possuem técnicas de corte que otimizam o corte. O que não tem como usar, caroço e partes mais estragadas, vão para o minhocario. Maça hoje só o talo vai para o minhocario e hoje é usado na farinha do biscoito. O abacaxi é fatiado na maquina vai para a bacia para depois ser colocado nas secadoras. E o caldo sai todinho isso é uma delicia. E ai sai cerca de 30 a 40 litros de liquido por dia. A gente não tinha onde colocar e as aparas das cascas que descascamos na maquina e aparamos manualmente. E estamos negociando com uma loja de polpa de fruta para podermos levar. A coroa já fica ali vai para o balde e vai para o carrinho que vai para a compostagem.
\end{abstract}

A ecogastronomia está ligada pela presença, no que Beck (2010) chama de segunda modernidade, do medo e do risco. O próprio conceito de ecogastronomia surge como consequência de uma ansiedade alimentar causada pelo risco. Este risco, para os participantes do Movimento Slow Food, está associado às questões sociais, ambientais e de saúde. Quando a segunda modernidade surge também se estipula uma separação entre tempo-espaço (GIDDENS, 1991). Esta separação gera um circuito alimentar mais amplo e complexo, cheio de intermediários, e isto é um dos geradores da ansiedade alimentar. A chegada da comida industrializada e as altas especializações e divisões dentro do processo de produção alimentar acaba nos afastando da matéria prima e de sua real produção, fazendo surgir uma desconfiança com relação à alimentação, apesar de, aparentemente, cada vez mais haver uma vigilância alimentar mais rigorosa (POULAIN, 2013). Isto fica claro na fala de uma participante goiana e sua indignação com as relações sanitárias

Eu quero morrer com essa coisa de carimbo. Que tem tanta coisa errada por aí. Higiene tem que ter, eu fui criada comendo porco da fazenda, e ninguém morreu por 
causa disso, eu não tenho colesterol alto, não tenho diabete, não tenho nada. Isso se chama deshigiene.

\section{CONSIDERAÇÕES FINAIS}

Ao conviver com produtores, cozinheiros, nutricionais e pessoas engajas em garantir um alimento "bom, limpo e justo" tive a possibilidade de refletir sobre a relevância do consumo de produtos traduzidos localmente e endêmicos. Propõem-se, assim, que por trás de cada ser humano existem barus, juçaras, milhos, Paellas... E essas pessoas são identificas e se identificam, dentre outras coisas, através dessas plantas e de seus preparos. Paranaenses e catarinenses possuem uma representação do pinhão e o pinhão é representado a partir do paranaense e catarinense. As raízes das araucárias entrelaçam-se com as raízes dos sujeitos. Especificamente neste ponto não pretendi entrar em discussão de gosto. Não é porque se é de determinada região que se deva gostar de determinado fruto ou prato típico. Mas sem dúvida este fruto e prato típico estão associados à sua identidade regional, não importando se seu almoço de hoje foi um Big Mac.

Desta maneira, a antropologia da alimentação nos dá, não somente a possibilidade de refletir sobre essas tensões alimentares criadas pela modernidade, como também as mudanças e permanências de certos pratos e ingredientes na culinária vinculando-se ao meio e aos arranjos sociais. Em especial através de ingredientes, rituais e formas de comer podemos observar elementos de forte expressão cultural de um povo, ou seja, falar sobre um grupo ou comunidade através do que se come ou deixa de comer. Isto nos possibilita mostrar que não alimentamo-nos apenas pelas necessidades nutricionais, mas sim que a comida também alimenta a sociedade de forma a distinguir grupos e criar categorias sociais. Para meu trabalho a antropologia da alimentação me deu subsídios e base para que possamos entender as relações que se criam e certos conflitos que se estabelecem nas sociedades. Especialmente quando saímos de uma localidade e vemos a pluralidade, isto é, foi ao sair de Florianópolis, percorrer vários caminhos pude perceber que a comida que caminha cada vez mais rapidamente entre os portos, aeroportos, estradas indo e vindo de vários estados, países, continentes trazem consigo um local, uma identificação, uma marca regional.

Por fim, e não menos importante, pode-se notar uma visão de resgate ao processo produtivo alimentar, desalientando os consumidores de seus alimentos. Compreendendo que cada grão de feijão tem um produtor que arou a terra, plantou, regou, colheu e que assim a ecologia está presente em cada prato. Concluímos assim que comer é ecologizar. 


\section{REFERÊNCIAS}

ANDREWS, Geoff. Slow food: una storia tra politica e piacere. Bologna, Il Mulino, 2010.

ASSUNÇÃO, Viviane K. Circulação de alimentos e de relações entre brasileiros em Boston e no Brasil. In: Rial, Carmen; Silva, Sandra R.; Souza, Ângela M. (comps.) Consumo e cultura material: perspectivas etnográficas. Florianópolis, Editora da Ufsc, 2012, pp. 75-90.

BALÉE, William. "Biodiversidade e índios amazônicos", en: Castro, Eduardo Viveiros de y Cunha, Manuela Carneiro da (comps.): AMAZÔNIA: etnologia e história indígena. São Paulo, Núcleo de História Indígena e do Indigenismo da Usp, Fapesp, 1993, pp. 385-393.

BECK, Ulrich. O que é Globalização? Equívocos do globalismo: respostas à globalização. São Paulo, Paz e Terra, 1999.

Sociedade de risco: Rumo a uma outra modernidade. São Paulo, Editora 34, 2010.

BOURDIEU, Pierre. A Distinção: crítica social do julgamento. Porto Alegre, Editora Zouk, 2006.

CASTELLS, Manuel. A sociedade em rede. São Paulo, Paz e Terra, 1999.

DAMATTA, Roberto. Sobre comidas e mulheres. In: O que faz o brasil Brasil. Rio de Janeiro: Rocco 1987.

DOUGLAS, Mary. Pureza e Perigo Ensaio sobre as noções de Poluição e Tabu. Lisboa, Edições 70 (col. Perspectivas do Homem, n. ${ }^{\circ}$ 39), 1966.

FISCHLER, Claude. "Round table "To accelerate the prevention of childhood obesity: forging a societal action plan that works". In: Health Challenge Think Tank. Montreal, 2006.

GIDDENS, Anthony. As consequências da modernidade. São Paulo, Unesp, 2991.

GOLDENBERG, Mirian. Cultura e gastro-anomia: psicopatologia da alimentação cotidiana. Entrevista com claude fischler. In: Horizontes Antropológicos, Ano 17, No. 36, 2011, pp. 235-256.

GOODY, Jack. Comida, cozinha e classe: Um estudo da sociologia comparativa. Oeiras, Celta Editora, 1998.

HARRIS, Marvin. Vacas, porcos, Guerras, bruxas. Os enigmas da cultura. Rio de Janeiro, Civilização brasileira, 1978.

LE BRETON, David. Antropologia dos sentidos. Rio de Janeiro: Vozes, 2016.

MACIEL, Maria Eunice. Cultura e alimentação ou o que tem a ver os macaquinhos de Koshima com Brillat-savarin?. In: Horizontes Antropológicos, Ano 7, $\mathrm{N}^{\circ}$ 16, 2011, pp. 145156. 
MILLER, Daniel. Consumo como cultura material. In: Horizontes Antropológicos, Ano 13, $\mathrm{N}^{\circ} .28,2007$, pp. 33-63.

RENNER, Estela. Muito Além do Peso. São Paulo, Mari Farinha Filmes (90 min.), son., color, 2012.

PETRINI, Carlo. Slow Food: princípios da nova gastronomia. São Paulo, Editora SENAC São Paulo, 2009.

POULAIN, Jean-Pierre. Sociologias da alimentação: os comedores e o espaço social alimentar. Florianópolis, Editora da UFSC, 2013.

POLLAN, Michael. Cozinhar: Uma história natural da transformação. Rio de Janeiro, Intrínseca, 2014.

PORTILHO, Fátima. Novos atores no mercado: movimentos sociais econômicos e consumidores politizados. In: Política \& Sociedade, Vol. 8, 2009, pp. 199-224.

RIAL, Carmen. Mar-de-Dentro: a transformação do espaço social na Lagoa da Conceição. Porto Alegre: Dissertação (Mestrado) - Curso de Antropologia Social, Universidade Federal do Rio Grande do Sul, 1988.

SALHINS, Marshall. Cultura e razão prática. Rio de Janeiro, Jorge Zahar Editor, 2003. "AUTOR” (2015).

SIMMEL, Georg. A natureza sociológica do conflito. São Paulo, Editora Ática, 1983.

SPITZCOVSKY, Débora. Chef Atala lança instituto em prol da culinária sustentável. In: Planeta Sustentável. São Paulo, Editora Abril, 2013.

TSING, Anna. Margens Indomáveis: cogumelos como espécies companheiras. In: Ilha revista de antropologia, Vol. 17, $\mathrm{N}^{\circ} .1,2015$, pp. 177-201.

VIEIRA, Paulo H. F.; GUERRA, M. P. Biodiversidade, Biotecnologias e Ecodesenvolvimento. Florianópolis, editora UFSC, 1995. 